\title{
"ANÁLISE RETROSPECTIVA DA TOXICIDADE DE GOTAS OTOLÓGICAS, MEDICAMENTOS TÓPICOS NASAIS E OROFARÍNGEOS REGISTRADA NA GRANDE SÃO PAULO"
}

Quanto ao artigo em referência publicado nesta edição, à página 433, em 2004, a Agência Nacional de Vigilância Sanitária (ANVISA) determinou que todos os medicamentos de prescrição contenham em suas embalagens dois tipos de informações sobre o produto: a bula para o paciente e a bula para os profissionais de saúde. Isto visa informar e alertar o usuário sobre a utilização do medicamento, reinterando as orientações e prescrição médicas. Isto tem particular importância em evitar os eventos adversos relacionados as intoxicações por superdosagem, interações medicamentosas e erro de utilização. Infelizmente, em nosso país, os usuários podem adquirir medicamentos de prescrição sem a necessidade de apresentar uma receita. Muitas vezes o próprio farmacêutico ou farmacista indicam o medicamento e sua posologia. Como a ANVISA ainda não conseguiu operacionalizar a fiscalização efetiva das farmácias, todos os cuidados de informação devem ser veiculadas e disseminadas no meio médico. Estudos retrospectivos e/ou prospectivos devem ser realizados a fim de acumular dados para determinar os riscos de um determinado medicamento ou de um indivíduo dentro de uma determinada população. Além disso, o treinamento dos profis- sionais de saúde deve ser intensificado, pois tal matéria não faz parte dos seus respectivos currículos. Cabe aqui discutir o conceito de farmacovigilância definida pela Organização Mundial de Saúde como "a ciência e atividades relacionadas à detecção, determinação e prevenção de eventos adversos ou qualquer outro problema relacionado a medicamentos". Portanto, devemos estar atentos para a farmacovigilância de medicamentos seja ela na sua fase experimental ou pós-comercialização, seja ela passiva ou ativa. "Evento Adverso (EA)" e o desenvolvimento de uma condiçãa médica indesejável ou deteriorização de uma condição médica preexistente após ou durante a exposição de um produto farmacêutico, seja ele ou não considerado relacionado ao produto. Esta condição pode ser um sintoma (náusea, dor torácica), sinais (taquicardia, hepatomegalia) ou exames anormais (achados laboratoriais, electrocardiograma). Já um "Evento Adverso Sério" (EAS) e um EA que ocorre com qualquer dose de um medicamento e preenche um ou mais dos seguintes acontecimentos: ? I) resulta em morte; 2) perigo de morte iminente; 3) requer hospitalização ou prolongamento de uma hospitalização existente; 4) resulta em incapacidade física significativa ou persistente;
5) resulta em anormalidade ou defeito congênito ou 6) seja um evento médico que pode comprometer o indíviduo ou que requer intervenção médica para prevenir um dos eventos anteriormente listados. A fonte do relato pode ser um profissional de saúde, um consumidor, uma publicação, autoridades regulatorias, comitês de segurança, advogado ou estudos clínicos entre outros. Cabe também definir que superdosagem e definida como uma dose administrada a um indíviduo em excesso daquela especificada pela informação do produto. Não significa automaticamente que seja um EAS, a não ser que preencha a definição anteriormente citada. Suicídio ou tentativa de suicídio, independente do método, deve ser considerada como EAS. Tal é a importância deste assunto que o órgão regulatório Americano FDA (Federal Drug Association) possui mais de 2 milhões de EAS sobre medicamentos e produtos biológicos. Tais informações são extremamente importantes para a avaliação de um medicamento, seu hábito prescritivo, como está sendo utilizado pelos consumidores e na determinação de novas orientações de utilização em qualquer fase de seu desenvolvimento.

Marcelo Marotti 